\title{
ДВОЙНОЙ ПЕРЕХОД СТРАН К ЦИФРОВОЙ И «ЗЕЛЕНОЙ Э ЭКОНОМИКЕ: ВОЗМОЖНОСТИ И УГРОЗЫ
}

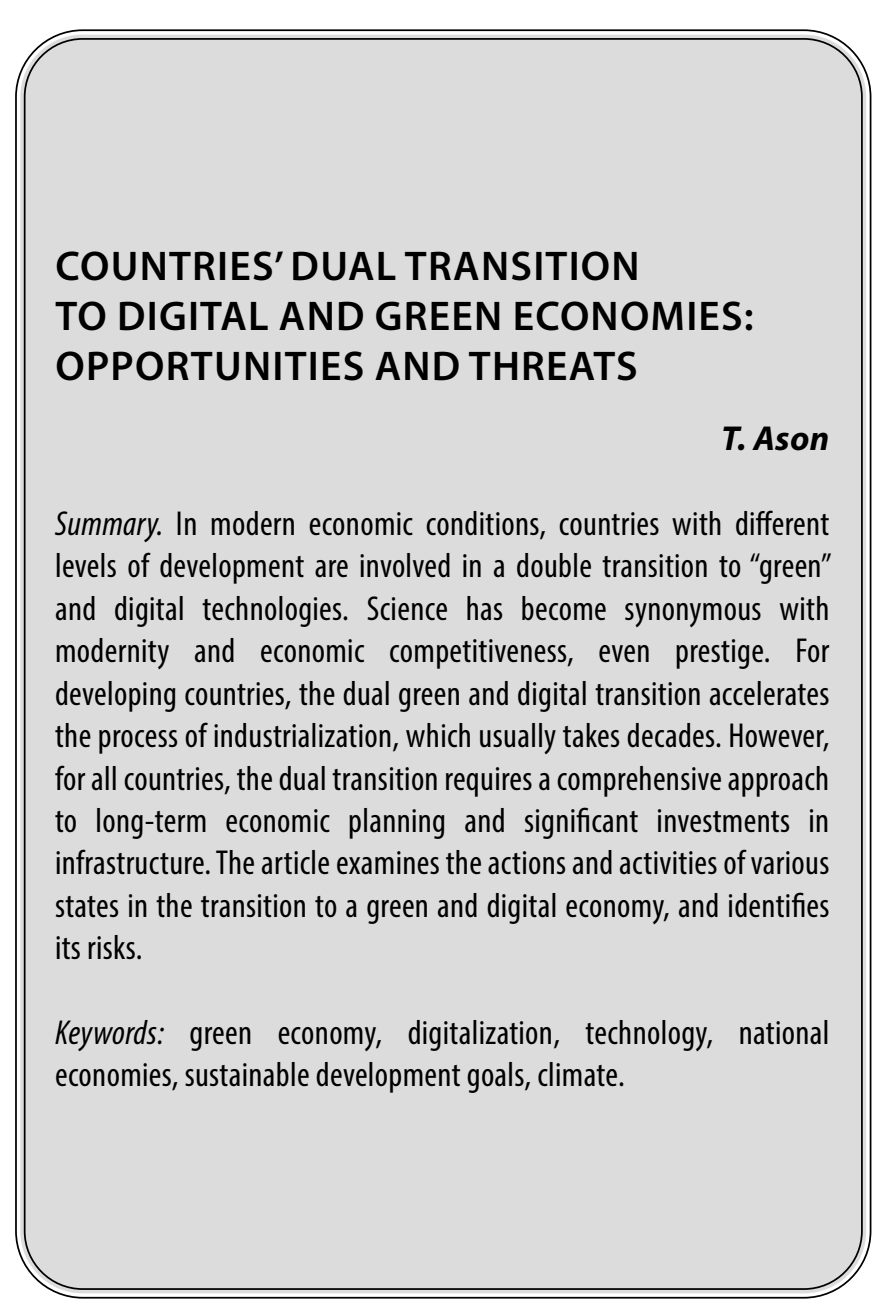

C

2015 года большинство стран стали приводить свою национальную политику в соответствие с целями устойчивого развития 2030 (ЦУР), и тем самым, осуществлять постепенный переход к «зеленой» экономике. Правительства наращивают объемы поддержки «умных» систем производства и потребления. По мере роста соотношения затрат и выгод от возобновляемых источников энергии число «зеленых» энергетических проектов увеличивается. Однако многие правительства беспокоятся о том, как согласовать сохранение рынков и рабочих мест с их приверженностью Парижскому соглашению. Несмотря на растущее воздействие изменения климата, со стороны правительств и бизнеса по-прежнему недостаточно мер для необходимого перехода к «чистой» энергетике. Так, в 2018 году более 80\% мирового производства энергии было основано на угле, нефти и газе.

\author{
Асон Татьяна Анатольевна \\ К.э.н., доцент, ФГБОУ ВО «Финансовый университет \\ при Правительстве Российской Федерачии» \\ tatiana_ason@mail.ru
}

Аннотация. В современных условиях хозяйствования страны с различным уровнем развития участвуют в двойном переходе к «зеленым» и цифровым технологиям. Наука стала синонимом современности и экономической конкурентоспособности, даже престижа. Для развивающихся стран двойной «зеленый и цифровой» переход ускоряет процесс индустриализации, который обычно занимает десятилетия. Однако, для всех стран двойной переход требует комплексного подхода к долгосрочному планированию экономики и значительных инвестиций в инфраструктуру. В статье рассматриваются действия и мероприятия различных государств при переходе к «зеленой» и цифровой экономике, а также определены его риски.

Ключевые слова: «зеленая» экономика, цифровизация, технологии, национальные экономики, цели устойчивого развития, климат.

Параллельно с переходом к «зеленым» технологиям страны переводят государственные услуги и платежные системы в цифровую платформу для улучшения предоставления услуг, поддержки бизнеса, а также борьбы с коррупцией и уклонения от уплаты налогов. Политика многих государств способствует возникновению цифровой экономики, включая интеллектуальное производство, интеллектуальные финансы (финтех), интеллектуальные услуги здравоохранения, такие как телемедицина и интеллектуальное сельское хозяйство.

Стоит отметить, что пандемия COVID -19 выявила зависимость ряда стран от глобальных цепочек создания стоимости в отношении стратегических ресурсов. Сложность компонентов современных устройств означает, что производители прибегают к услугам субподрядчиков за рубежом, специализирующиеся 
в узкой области, которые, в свою очередь, полагаются на других поставщиков основных материалов. Так, Европейский Союз (ЕС) зависит от импортной продукции, к примеру, микропроцессоров, а для ключевых производств - от импортного сырья, такого как редкоземельные ресурсы. В первом ежегодном докладе Европейской комиссии «Стратегическое прогнозирование до 2020 года: Charting the Course Towards a More Resilient Europe 2020» [6] данная зависимость отмечается как потенциальная угроза для европейского экономического суверенитета. Перенеся в 80-х годах 20 столетия большую часть своего производства в развивающиеся страны с дешевой неквалифицированной рабочей силой, промышленно развитые страны в первые дни пандемии оказались зависимы от импорта средств индивидуальной защиты и обычных лекарств, таких как парацетамол. Китай, обладающий достаточно развитым производственным сектором, по-прежнему, зависит от импорта некоторых ключевых технологий, например полупроводников. Эта технологическая уязвимость иллюстрируется судьбой китайской компании ZTE, которая была вынуждена свернуть большую часть своей деятельности в течение нескольких недель после того, как в апреле 2018 года была отрезана от американских поставщиков аппаратных компонентов и сервисов Android (Google)[7].

Отчасти именно из-за желания уменьшить зависимость от американских поставщиков высоких технологий китайское правительство в 2015 году запустило десятилетнюю государственную промышленную политику под названием «Сделано в Китае 2025». Такая политика поощряет китайские компании расширять свою долю на мировом рынке, в частности, электромобилей, передовой робототехники и искусственного интеллекта, сельскохозяйственных технологий, аэрокосмической техники, новых синтетических материалов и другой высокотехнологической продукции [2].

До пандемии COVID -19 развитые страны инвестировали в передовые производственные технологии, чтобы оживить свой внутренний производственный сектор. В 2016 году федеральное правительство США определило приоритетность ключевых стратегических платформ в области цифровых технологий: искусственный интеллект, квантовые технологии, передовые технологии мобильных сетей и кибербезопасность. Для этих целей был разработан стратегический план по переходу промышленности на новые производственные технологии, подготовке рабочей силы в сфере производства и расширении возможностей отечественной логистики.

Также, обновленная промышленная политика ЕС поддерживает развитие стратегически важных технологий для промышленного будущего Европы. К ним от- носятся робототехника, микроэлектроника, блокчейн, квантовые технологии, промышленная биотехнология, биомедицина, нанотехнологии, фармацевтика и современные материалы. В 2020 году в докладе Европейской комиссии «Новая промышленная стратегия для Европы» подчеркивается важность сохранения технологического суверенитета и стратегических интересов Европы в области торговли и технологий таких областей, как искусственный интеллект и связанные с ним цифровые технологии и инфраструктура [1].

Цифровые технологии считаются жизненно важными для будущей экономической конкурентоспособности многих стран мира. Особенно стоит выделить развитие ИИ и робототехники, именно данные области доминируют в научной публицистике в 2018-2019 годах в странах независимо от уровня дохода.

Многие страны создали институциональные механизмы для содействия внедрению технологий Индустрии 4.0. Например, в Южной Африке в 2019 году была создана Президентская комиссия по четвертой промышленной революции, в состав которой вошли около 30 заинтересованных сторон, представляющих научные, промышленные и правительственные круги. В Республике Корея с 2017 года действует Президентский комитет по четвертой промышленной революции. В Австралии работает Агентство цифровой трансформации, созданное в 2015 году, которое способствует сотрудничеству с промышленными группами Германии и США. Стратегия I-Korea Республики Корея (2017) ориентирована на новые факторы роста экономики, включающие искусственный интеллект, беспилотники и автономные автомобили. Также, в октябре 2020 года Уганда приняла собственную Национальную стратегию 4IR с упором на электронное управление, городское управление (умные города), здравоохранение, образование, сельское хозяйство и цифровую экономику. Цифровая экономика находится и в центре внимания Стратегического плана «Цифровой Камерун-2020» (2017). В Камеруне создан центр высоких технологий, специализирующийся на робототехнике, цифровом производстве и компьютерном зрении, а также уникальный для стран Африки южнее Сахары центр 3D-печати [9].

Определённо некоторые страны стремятся стать региональными цифровыми центрами, такие как Австралия, Джибути, Марокко. Однако большинство предприятий еще не перешли на цифровые технологии. Руководство предприятий не всегда поддерживают цифровой переход либо из-за отсутствия мотивации, либо из-за отсутствия возможностей. Многие компании продолжают импортировать технологии, а не разрабатывать свои собственные. Они часто неохотно идут на сотрудничество с государственными научно-иссле- 
довательскими институтами, что заставляет правительства различных государств разрабатывать новые стимулы для содействия передаче технологий, например, путем создания лабораторий, где предприятия могут «протестировать, прежде чем инвестировать» в цифровые технологии. Австралийская стратегия «Индустрия 4.0», Tech Future (2018), предлагает создать «тестовые лаборатории» в пяти университетах, чтобы помочь компаниям перейти к «умным» предприятиям.

Для успешного осуществления двойного перехода правительствам необходимо повысить свою приверженность научным исследованиям и разработкам (НИОKP). На долю стран G20 по-прежнему приходится девять десятых расходов на исследования, публикации и патенты. Хотя расходы на исследования выросли в большинстве регионах в период с 2014 и 2018 гг, 80\% стран по-прежнему инвестируют менее 1\% ВВП в НИОКР [8].

Государство Малайзии помогает компаниям оцифровать свои бизнес-процессы с помощью гранта Smart Automation Grant, запущенного Корпорацией цифровой экономики Малайзии в июле 2020 года в рамках Национальной политики в области промышленности 4.0, предназначенного для компаний сектора услуг. В 2021 году должен быть запущен Центр опыта «умного производства», который предоставит МСП доступ к существующим платформам и технологиям, чтобы обеспечить им «испытательный полигон» для тестирования своих инноваций [8].

В период с 2016 по 2020 год более 30 стран мира приняли специальные стратегии в области искусственного интеллекта. Китай, Российская Федерация и США борются за конкурентное преимущество в области самого ИИ. Президент России Владимир Путин в 2017 году заявил, что «тот, кто станет лидером в этой сфере, станет правителем мира». Согласно плану развития искусственного интеллекта нового поколения, к 2030 году Китай намерен стать «главным мировым центром инноваций в области ИИ». Китай уже является крупнейшим в мире владельцем патентов на ИИ, но ему не хватает талантливых специалистов в этой области[4]. В свою очередь, США в 2020 году значительно увеличил расходы на науку по квантовой информации искусственного интеллекта.

Большинство стран убеждены, что их будущая экономическая конкурентоспособность зависит от того, насколько успешно они осуществят переход к цифровому обществу. Между тем, принятие ЦУР в 2015 году в сочетании с растущими издержками неустойчивого развития и последствиями изменения климата сделали «зеленый» переход стран приоритетной повесткой дня. Быстрый экономический рост, усиление зависимости от технологий и повышение температуры климата приводят к росту потребностей энергии. Например, в течение последних двух десятилетий в Центральной Азии экономический рост привел к повышению спроса на электроэнергию, увеличению выбросов углекислого газа и сокращению экспортных доходов: $86 \%$ узбекского природного газа в настоящее время используется для внутреннего потребления [8].

Правительства многих стран осознают, что их будущая экономическая конкурентоспособность будет зависеть от того, насколько быстро им удастся перейти к «зеленой» и цифровой экономике одновременно. Эта двойная повестка дня отражена, например, в стратегиях стран Карибского бассейна. В 2018 году государства-члены создали Карибский центр по возобновляемым источникам энергии и энергоэффективности.

Промышленная политика ЕС (2021) опирается на три столпа: зеленый переход, цифровой переход и глобальная конкурентоспособность. В период с 2021 по 2027 годы интеграционное объединение планирует потратить 1,8 триллиона евро государственных средств, 30\% из которых будет инвестировано в двойной переход стран к «зеленой» и цифровой экономике [1]. Одним из направлений «зеленого» перехода станет циркулярная экономика. В 2018 году Российская Федерация, воспользовавшись ротационным председательством в Евразийском экономическом союзе (ЕАЭС), предложила ряд направлений «перенастройки» Союза, включая формирование общего цифрового пространства и энергетического рынка для стран-членов, а также сотрудничество в области «зеленых» технологий, возобновляемых источников энергии, биоинженерии, нанотехнологий, экологии, медицины и космоса. Государства-члены стремятся создать «территорию инноваций», которая будет состоять из их преимуществ.

Как и другие развивающиеся государства, Тунис нуждается в диверсификации своей экономики с целью создания рабочих мест и привлечения ПИИ. Тунис выбрал путь развития наукоемких отраслей. В 2017-2018 годах приток ПИИ в Тунис вырос на 16\%, поскольку иностранные компании по производству электроники были привлечены в страну конкурентоспособной ценой на высококвалифицированную рабочую силу, особенно в автомобильном и авиационном подсекторах. В мае 2017 года 41 электронная компания с совокупным годовым объемом продаж около 1,2 млрд. долларов США создали свой собственный кластер ELENTICA, который в октябре 2018 года заключил партнерство с Министерством высшего образования и научных исследований Туниса с целью развития научного сотрудничества и создания исследовательских центров в компаниях ELENTICA. Данные исследовательские центры будут сосредоточены в таких областях, 
как умные города, возобновляемые источники энергии и интеллектуальные сетевые технологии, электромобили и электронное сельское хозяйство[9].

Примером двойного перехода является Япония. Столкнувшись с проблемой низкой рождаемости и старением населения, правительство приняло в 2017 году стратегию «Общество 5.0», позволяющая создать устойчивую, инклюзивную, социально-экономическую систему, основанную на цифровых технологиях. Цель - выйти за рамки «Индустрии 4.0» и преобразовать японский образ жизни. Правительство делает ставку на то, что Стратегия «Общество 5.0» позволит Японии преодолеть хронический экономический застой [5]. Несмотря на то, что Япония пока не занимает лидирующие позиции в цифровых отраслях, она может воспользоваться своими традиционными преимуществами в области машиностроения и материаловедения для разработки передовых киберфизических систем. Можно надеяться, что благодаря активному внедрению ИИ на рабочих местах депопуляция и старение населения будут остановлены.

Цифровизация экономики способствует более активному участию граждан в онлайн-операциях. Создание системы цифровых платежей в развивающихся странах позволяет увеличить объем электронной коммерции и борьбе с уклонением от уплаты налогов и коррупцией, но также, вероятно, повысит уязвимость тех, кто занят в неформальной экономике, где наличные платежи являются нормой. Примером может послужить Индия - страна с наличной экономикой. Чтобы сократить масштабы неформальной экономики, в 2016 году правительство пошло на радикальный шаг - демонетизацию двух банкнот, которые составляли около 86\% находившихся в обращении на тот момент. В период с 2014 по 2017 год доля граждан, имеющих банковский счет, выросла с 53\% до 80\%, а цифровой рынок расширился. Онлайн-платежи стали, особенно, привлекательным вариантом в Индии и других странах во время Covid-19, выступающими как средство соблюдения физического дистанцирования при финансовых операциях [9].

Индия старается модернизировать экономику своей страны, и в тоже время заниматься продвижением цифровой платформы для многих сфер жизнедеятельности. Помимо того, что индийское правительство расширяет доступ граждан к банковским онлайн- услугам, правительственный аналитический центр, Национальный институт по преобразованию Индии (NITI Aayog), в 2018 году опубликовал Национальную стратегию по искусственному интеллекту, призванную способствовать улучшению здравоохранения, образования и повышению урожайности сельского хозяйства. Данная стратегия направлена на развитие умных городов. Также NITI Aayog изучает возможности внедрения тех- нологий блокчейн в отрасли по производству лекарств и удобрений, электрических и гибридных транспортных средств в автомобильной промышленности и расширения возобновляемой энергетики.

Но существует риск, что «умные города» могут усугубить социальное неравенство. Речь идет о перспективе сокращения рабочих мест в крупных масштабах. В случае с цифровым переходом беспокойство вызывает автоматизация; в случае с «зеленым» переходом - постепенный отказ от крупных загрязняющих производств, таких как угольные станции, которые являются объектом массовой занятости. Однако, Европейская комиссия гарантирует, что рабочие места, потерянные в одной отрасли в результате перехода к цифровой и зеленой экономике, могут быть воссозданы в других отраслях. Механизм справедливого перехода помогает ограничить турбулентность в наиболее уязвимых стран-членов ЕС с помощью специальных ресурсов. Этот механизм является частью инвестиционного плана «Устойчивая Европа» Европейского зеленого курса, мобилизующего государственные и частные инвестиции на общую сумму не менее $€ 1$ трлн. [6].

Возобновляемые источники энергии - это еще один аспект внимания при «двойном переходе» стран. Возобновляемые источники энергии были единственным сектором энергетики, в котором наблюдался рост в разгар пандемии COVID-19, и спрос на них, по прогнозам будет расти и дальше. Возобновляемые энергетические системы стали экономически эффективными, чем альтернативные системы, благодаря технологиям ветряной и солнечной энергии.

Энергия лежит в основе как цифрового, так и «зеленого» перехода. В странах Африки к югу от Сахары только половина (48\%) населения имеет доступ к электричеству. Однако, очевидно, что без всеобщего доступа к энергии не может быть ни индустриализации, ни цифровой экономики. Поэтому в Стратегии Африканского союза «Повестка дня на 2063 год» [3] первоочередное внимание уделяется инвестициям в возобновляемые источники энергии в дополнение к расширению энергосистемы. В период с 2015 по 2018 год общая доля возобновляемых источников энергии в энергетических мощностях Южной Африки выросла с 24\% до 39\%. Большинство проектов касаются ветровой, солнечной и гидроэнергетики. В Восточной Африке геотермальная энергия в настоящее время подается в более чем 35\% кенийских домохозяйств. В ноябре 2019 года Кения обогнала Исландию и заняла восьмое место в мире по потенциалу для производства геотермальной энергии.

Вопрос строительства атомных электростанций также стоит пред странами при переходе к «зеленой» экономике. Имея срок службы около 40 лет, их строитель- 
ство обходится в миллиарды долларов. К 2025 году 25\% существующих ядерных мощностей, вероятно, придется закрыть. Однако, такие страны как Египет и Объединенные Арабские Эмираты, Монголия и Замбия планирует строительство АЭС и в дальнейшем.

В тоже время, Республика Корея развивает водородную энергию, чтобы компенсировать постепенный отказ от ядерной энергии в соответствии с Третьим энергетическим генеральным планом на 2019-2040 годы. Поскольку Республика Корея является ведущим производителем ядерных реакторов, существует определенная обеспокоенность тем, что отказ от ядерной энергии подорвет конкурентоспособность страны.

Некоторые развивающиеся страны сотрудничают с международными партнерами с целью получения доступа к «зеленому» финансированию. Например, в Казахстане были разработаны льготные тарифы аукциона по продаже солнечной энергии в рамках проекта Kazakhstan Renewables Framework, который с 2017 года софинансируется Европейским банком реконструкции и развития и Зеленым климатическим фондом.

Все большее число развивающихся стран используют доходы от добычи полезных ископаемых и разведки нефти и газа для финансирования «зеленой» экономики. В рамках Политики зеленого развития (2014-2030) Монголия планирует поддержку развития горнодобывающей и металлургической промышленности путем создания фонда национального благосостояния от доходов горнодобывающего сектора.

Однако, в промышленно - развитых странах процесс постепенного перехода на возобновляемые источники энергии встретил определенное сопротивление со стороны сторонников традиционной энергетики. Например, в течение четырех лет (2016-2019) после принятия Парижского соглашения, 35 банков из Канады, Китая, Европы, Японии и США совместно инвестировали 2,7 триллиона долларов США в ископаемое топливо[9].

Тем не менее, правительства стран стали вносить в повестку дня вопросы климатического характера. Например, Мозамбик инвестирует в климатоустойчивую инфраструктуру. В 2021 году Джибути планирует открыть свою Региональную обсерваторию по глобальным изменениям. В 2017 году Камбоджа выделила $1 \%$ государственных доходов на решение проблемы изменения климата в соответствии со Стратегическим планом Камбоджи по изменению климата 2014-2023. Но прогресс сдерживается отсутствием необходимых технологий и финансов [9].

Из всех целей устойчивого развития, связанные с экономическим ростом, именно те, которые сфокусированы на промышленности, инновациях и инфраструктуре (ЦУР 9) и устойчивых городах и сообществах (ЦУР 11), получили наибольший объем официальной помощи в целях развития на период 2000-2013 годах -130 млрд. долл. США. [8]. Темы, связанные с экологической устойчивостью (ЦУР12), действиям по защите климата (ЦУР13) получили наименьшее внимание доноров за тот же период.

Исследования в области устойчивого развития еще не стали основным направлением в академических публикациях на глобальном уровне. Так, исследования в области изменения климата, составили всего лишь 0,02\% глобальной научной продукции в период с 2011 по 2019 год.

В заключении стоит отметить, что реализация двойного перехода требует параллельных мероприятий как инвестиции в развитие инфраструктуры - центры обработки данных, высокопроизводительные вычислительные комплексы, солнечные и ветряные электростанции и т.д.- так и реформа нормативно-правовой базы и перестройка системы образования и профессионально-технической подготовки. Происходящие стремительные социальные преобразования открывают возможности для социальных и экономических экспериментов, которые могли бы сделать жизнь более комфортной. Для успешного осуществления двойного перехода правительствам необходимо не только увеличить расходы на НИОКР, но и инвестировать эти средства стратегически. Для этого потребуется разработка долгосрочной стратегии с учетом экономической, цифровой, экологической, промышленной и сельскохозяйственной политики государства. Чтобы быть последовательным в разработке стратегии, необходимо увязать реформы, политику и ресурсы с единой стратегической целью - устойчивое развитие.

\section{ЛИТЕРАТУРА}

1. Белов В.Б. Новая промышленная стратегия Евросоюза // Аналитические записки института Европы РАН. — 2020. — № 13 http://en.instituteofeurope. ru/publications/analytics/

2. Кристофилопулос Э., Манцанакис С. Китай -2025: научный и инновационный ландшафт // ФОРСАЙТ. — 2016. — № 3.— Том 10.— с. 7-16

3. Немченко В.П. Африканский Союз на пути обновления. // Азия и Африки сегодня.— 2019.— 5.— - 60 60 61 
4. Развитие искусственного интеллекта // ИА Красная весна. - 12.02 .2020

5. Щелкунов М.Д., Каримов А.Р. Общество 5.0 в технологическом, социальном и антропологическом измерениях // Вестник экономики, права и социологии. - 2019. — № 3.— с. 158-163

6. 2020 Strategic Foresight Report https://ec.europa.eu/info/strategy/strategic-planning/strategic-foresight/2020-strategic-foresight-report_en

7. Google Diversity Annual Report 2018

8. ITU. Fast-forward Progress: Leveraging Tech to Achieve the Global Goals. International Telecommunication Union: Geneva. — 2017

9. UNESCO SCINCE REPORT 2021

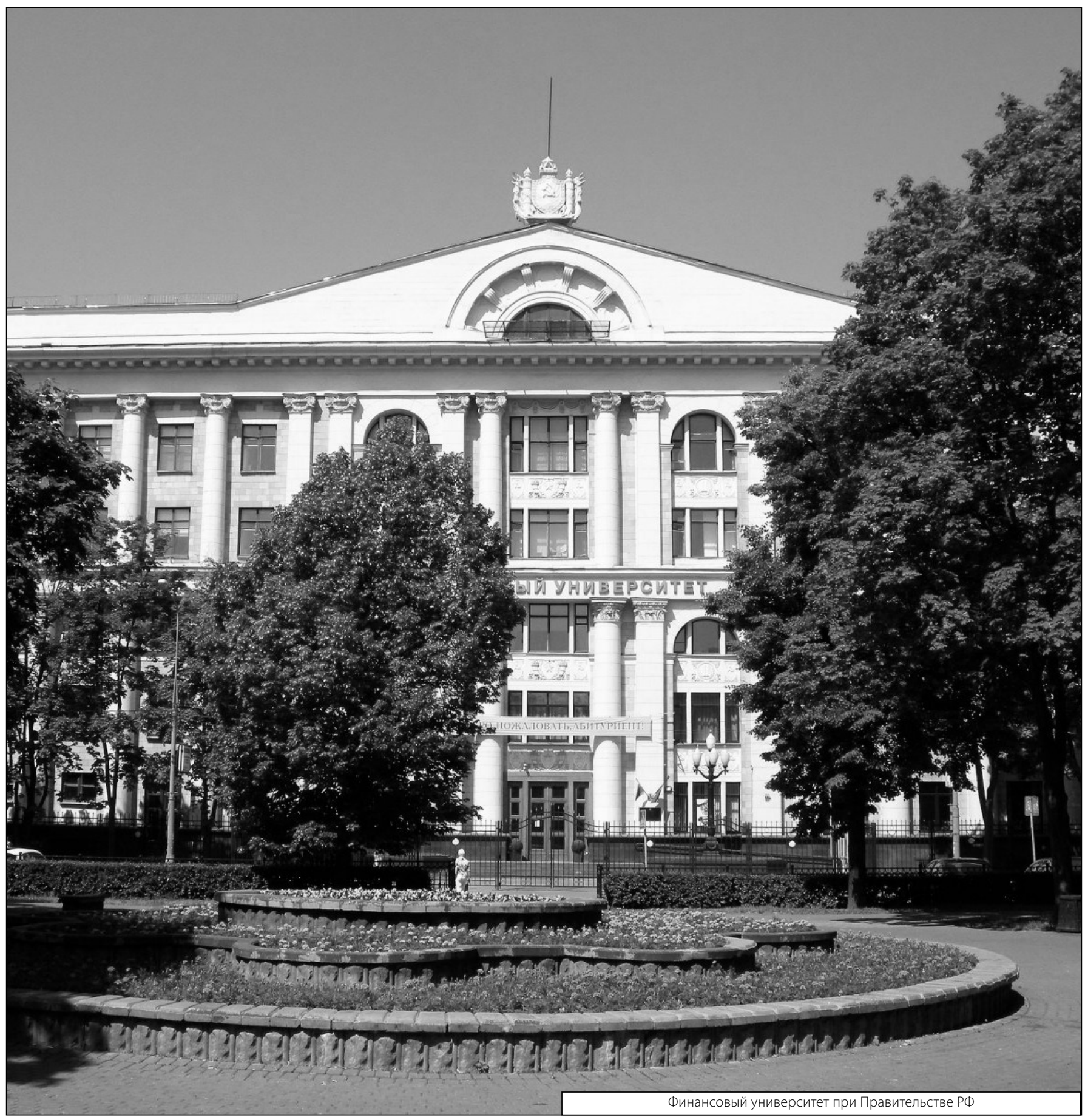

